\title{
GESTÃO ESCOLAR: DESAFIOS NA MEDIAÇÃO DAS RELAÇÕES DE CONVIVÊNCIA
}

\author{
GESTIÓN ESCOLAR: DESAFÍOS EN LA MEDIACIÓN DE RELACIONES DE \\ CONVIVENCIA
}

\section{SCHOOL MANAGEMENT: CHALLENGES IN THE MEDIATION OF RELATIONSHIPS OF COEXISTENCE}

\author{
Cristiane MACHADO ${ }^{1}$ \\ Angela Maria MARTINS ${ }^{2}$
}

RESUMO: Este trabalho integra investigação maior que analisa o Sistema de Proteção Escolar (SPE), programa de governo implementado em 2010 pela Secretaria de Estado de Educação de São Paulo. O objetivo é compreender, com base em dados obtidos em estudo exploratório, realizado em colaboração com Diretorias de Ensino Regionais, a opinião de 37 diretores escolares sobre relações humanas e profissionais no cotidiano escolar; relação da gestão com a rede de apoio e possíveis implicações de Professores Mediadores Escolar e Comunitário (PMECs) na dinâmica escolar. Identificou-se relativa contradição nas respostas dos diretores, embora seja perceptível o reconhecimento, da maior parte deles, da importância da função do PMEC na redução e mediação das situações de conflitos na escola.

PALAVRAS-CHAVE: Política pública. Gestão escolar. Conflitos escolares.

RESUMEN: Este trabajo forma parte del proyecto de investigación más amplio que analiza el Sistema de Protección Escolar (SPE), programa gubernamental implementado en 2010 por la Secretaría de Educación del Estado de Sao Paulo. El objetivo es comprender, basado en datos de estudio exploratorio, realizado en colaboración con los directores regionales de Educación, la opinión de 37 directores de escuelas en las relaciones humanas y profesionales en la vida escolar; gestión de las relaciones con la red de apoyo y las posibles implicaciones de Maestros Escuela y Comunidad Mediadores (PMECs) en la dinámica escolar. Fue identificado en la contradicción en las respuestas de los directores, aunque el reconocimiento es notable, con la mayor parte de ellos, la importancia del papel del CEIP en la reducción y la mediación de situaciones de conflicto en la escuela.

PALABRAS CLAVE: Políticas públicas. La gestión de la escuela. Conflictos escolares.

\footnotetext{
${ }^{1}$ Universidade Estadual de Campinas (Unicamp). Departamento de Políticas, Administração e Sistemas Educacionais (Depase) da Faculdade de Educação. Doutora em Educação. E-mail: crimacha@unicamp.br ${ }^{2}$ Universidade Cidade de São Paulo. Professora do PPGE. Pesquisadora Senior da Fundação Carlos Chagas. Pós-doutorado em Políticas Educacionais pelo Instituto de Psicologia e Ciências da Educação da Universidade de Lisboa. E-mail: ange.martins@uol.com.br
} 
ABSTRACT: This work integrates larger research that analyzes the School Protection System (SPE), a government program implemented in 2010 by the State Department of Education of São Paulo. The objective is to understand, based on data obtained in an exploratory study, carried out in collaboration with Regional Teaching Offices, the opinion of 37 school directors on human and professional relations in school daily life; Relationship of the management with the support network and possible implications of School and Community Mediator Teachers (PMECs) in the school dynamics. A relative contradiction was identified in the directors responses, although the acknowledgment of most of the importance of the PMEC's role in the reduction and mediation of conflict situations in school is perceptible.

KEYWORDS: Public policy. School management. Conflicts in school.

\section{Introdução}

O protagonismo da gestão no contexto escolar tem sido constante objeto de reflexão de estudos e pesquisas, especialmente depois da promulgação da Constituição de 1988, que abriu o caminho para uma educação democrática gestada pelos profissionais da educação escolar em articulação com a comunidade educacional. Este artigo insere-se nesse contexto e busca apresentar e analisar dados de pesquisa de campo tendo como ponto de partida a pergunta: o que pensam os diretores sobre as relações de convivência, as situações de conflitos e o papel do Professore Mediador Escolar e Comunitário (PMEC) na mediação destas situações?

Este estudo integra investigação maior ${ }^{3}$ sobre o Sistema de Proteção Escolar (SPE) instituído pela Secretaria de Estado da Educação de São Paulo (SEESP) por meio da Resolução SE 19, de 12/02/20104, realizada em parceria com Diretorias de Ensino Regionais do Estado de São Paulo (DERs) com a participação de equipes técnicas centrais desses órgãos, Professores Mediadores Escolar e Comunitário, diretores e alunos. A pesquisa toma como pressuposto que as escolas configuram um campo de disputas expressas ou dissimuladas e, como em qualquer outra organização, as pessoas e

\footnotetext{
${ }^{3}$ Os dados analisados neste trabalho se inserem na pesquisa "Conflitos no espaço escolar: a gestão de escolas públicas em contextos vulneráveis”, cujo propósito é identificar e compreender os motivos pelos quais escolas públicas da rede de ensino estadual paulista - localizadas em regiões consideradas vulneráveis -, aderem ao Programa Sistema de Proteção Escolar (SPE) e de que forma enfrentam situações de conflito e violência.

${ }^{4}$ O Sistema de Proteção Escolar possui o objetivo de instaurar na rede pública de escolas do estado de São Paulo ações para prevenir, mediar e solucionar conflitos. O programa foi implantado de forma descentralizada e gradativa e, para operacionalizá-lo, a SEESP criou a função do Professor Mediador Escolar e Comunitário (PMEC), responsável pela mediação de conflitos na rede pública de ensino paulista.
} 
os grupos reúnem-se em torno de interesses imediatos ou que se podem materializar em curto prazo de tempo, particularmente quando diretrizes legais são preconizadas por órgãos centrais.

Neste artigo, explora-se a opinião de 37 diretores das escolas estaduais de uma Diretoria Regional de Ensino de Região Metropolitana de Santos, com base nos dados obtidos em oficina realizada especialmente com esta finalidade. Naquela oportunidade foi solicitado que os diretores respondessem a um instrumento semiestruturado organizado em quatro blocos. Após a sistematização dos dados as respostas foram agrupadas em quatro dimensões: Quem são os diretores?; Relações humanas e profissionais no cotidiano escolar; Gestão escolar e rede de apoio; PMECs e possíveis implicações na dinâmica escolar.

\section{Contexto da pesquisa: aspectos legais que incidem na gestão de escolas no Estado de São Paulo}

A Secretaria de Estado da Educação de São Paulo é composta por 5.340 escolas, agrupadas em 91 Diretorias de Ensino Regionais (DERs), que atendem a educação básica nos níveis ensino fundamental e ensino médio, nas modalidades regular e EJA (Ensino de Jovens e Adultos). De acordo com dados de 2014, possui 233.127 professores, 6.942 especialistas de suporte pedagógico (dirigentes regionais, supervisores de ensino, diretores de escola e coordenadores pedagógicos), 7.755 vicediretores, 11.781 professores coordenadores, totalizando 26.478 gestores, 4.900 .000 alunos no estado, destacando-se, nesse contexto, peculiaridades sociais, políticas, econômicas e culturais diversas.

No que tange às funções preconizadas para diretores de escolas, a Resolução SE 52, de 14-8-2013 estabelece um rol de competências previstas, dentre as quais: conhecer a função social da educação escolar e saber usar a língua portuguesa (oral e escrita), em todas as situações sociais e atividades; compreender que a educação formal promove o desenvolvimento integral do aluno; compreender as dimensões da diferença, da diversidade e do multiculturalismo; conhecer os problemas e conflitos que afetam o convívio social (saúde, segurança, dependência química, educação para o trânsito, pluralidade cultural, ética, sustentabilidade ambiental, orientação sexual, trabalho e consumo); compreender como eles podem provocar preconceitos, manifestações de 
violência e impactos sociais, políticos, econômicos, ambientais e educacionais, reconhecendo a si mesmo como protagonista e agente transformador no âmbito de sua atuação profissional; aprimorar a capacidade de transformação, iniciativa, criatividade, assim como das implicações éticas e políticas do seu trabalho, pois vivemos em uma sociedade heterogênia e plural, onde se deve respeitar e valorizar as diferenças.

Chama a atenção ainda os critérios estabelecidos no que se refere à relação Escola e Comunidade, preconizando que os diretores devem compreender a escola como parte da comunidade escolar, tendo em vista que é constituída pelos professores, equipe gestora, alunos, funcionários, pais e/ou responsáveis pelos alunos. O texto legal também ressalta a necessidade de desenvolver parcerias com a comunidade escolar, considerando o entorno da escola e demais organizações e instituições, com vistas a construir espaços coletivos de participação entre escola, família e comunidade.

As disposições legais preveem que diretores exerçam suas funções atendendo adequadamente às demandas sociais e culturais de diferentes segmentos que integram o espaço escolar, em consonância com projetos político-pedagógicos coerentes às necessidades específicas de aprendizagem dos alunos. Recomendação que encontra eco no entendimento de Koetz (2010, p. 166) de que o diretor deve,

[...] procurar mecanismos que possibilitem a superação dos obstáculos, muitos decorrentes da própria estrutura e organização dos sistemas de ensino e das unidades escolares, bem como dos conflitos gerados pela diversidade cultural existente no cotidiano escolar.

Entretanto, a literatura da área vem indicando de forma recorrente problemas e desafios na gestão escolar nas relações cotidianas de trabalho, uma vez que a escola é, ao mesmo tempo, o lócus privilegiado de produção e apropriação de diferentes saberes sociais e culturais e reconhecidamente objeto de regulação do sistema educativo, configurando-se em "lugar estratégico para sua mudança" (BARROSO, 1996, p. 09). Assim, a escola é tensionada tanto por movimentos micros como, também, por movimentos macros que reverberam na gestão da escola, mais especificamente, na figura do diretor.

Há que se relevar, ainda, que de acordo com a LDB 9394/96 a gestão escolar deve primar por constituir a educação escolar de forma democrática e com a finalidade de desenvolver de maneira plena o educando, preparando-o para o exercício da cidadania e oportunizando-lhe conhecimentos para o seu progresso em estudos posteriores e no trabalho, aproximando a gestão escolar de, 
[...] uma concepção ampla de gestão que considere a centralidade das políticas educacionais e dos projetos pedagógicos das escolas, bem como a implementação de processos de participação e decisão nessas instâncias, balizados pelo resgate do direito social à educação e à escola, pela implementação da autonomia nesses espaços sociais" (DOURADO, 2007, p. 924).

\section{Percurso metodológico}

Em oficina de trabalho realizada em Diretoria Regional de Ensino de Região Metropolitana de Santos, solicitou-se que os diretores respondessem um instrumento semiestruturado, organizado em quatro blocos: a) o primeiro bloco com questões referentes ao perfil do respondente com o objetivo de contextualizar a formação, tempo na rede e cargos ocupados pelos respondentes; b) no segundo bloco de questões foi solicitado que os entrevistados assinalassem se as afirmações feitas aconteciam na sua escola frequentemente, às vezes ou nunca em relação aos alunos, professores, funcionárias e às regras estabelecidas, além de identificar os três espaços físicos ou temporais onde as ocorrências de situações de conflito mais aconteciam na sua escola; c) no terceiro bloco, solicitou-se que os diretores apontassem quais órgãos ou atores eles acionam para solucionar alguns as dificuldades nas situações de conflito e, d) o quarto bloco, com questões específicas em relação às funções do PMEC, solicitou-se que eles as descrevessem apontando se a presença do professor mediador gerou mudanças na escola, quais ações ele desenvolve e quais as principais dificuldades no desempenho do trabalho.

As respostas dadas pelos diretores foram sistematizadas e, para uma melhor organização, exposição e compreensão dos dados, agrupadas em quatro dimensões: Quem são os diretores?; Relações humanas e profissionais no cotidiano escolar; Gestão escolar e rede de apoio; Professores Mediadores Comunitários Escolares: possíveis implicações na dinâmica escolar.

\section{Quem são os diretores?}

Corroborando estudos que apontam a feminização da profissão docente na educação básica (VIANNA, 2013), do total de 37 participantes, 31 deles são mulheres e 
apenas 6 são homens. A maior parte dos diretores, 28 exatamente, possui idade entre 41 e 60 anos e, quase a metade, 19 deles se identificam como brancos, 13 como pardos e 4 como pretos; 1 diretor não respondeu a questão.

Os diretores relatam possuir experiência na função, 23 deles afirmam ter mais de 21 anos no cargo e 7 diretores têm de 16 a 20 anos. Apesar disso, apenas 1 diretor disse estar há mais de 21 anos na mesma escola e 8 entre 10 e 15 anos; 11 afirmam ter menos de 1 ano na escola e 7 entre 1 e 3 anos, denotando possível rotatividade no exercício da função. Mais da metade dos gestores é efetiva no cargo, 21 diretores nesta condição. Afirmam, ainda, desenvolver a atividade de direção de forma exclusiva, 30 diretores afirmam não atuar em outros cargos.

A formação predominante dos diretores é em pedagogia, e, em alguns casos possuem, também, licenciatura em áreas específicas como letras, história, educação física, biologia, dentre outras. Apenas 2 diretores afirmaram ter formação específica no campo da gestão educacional.

\section{Relações humanas e profissionais no cotidiano escolar}

O segundo bloco do questionário solicitou que os diretores assinalassem frequentemente, às vezes ou nunca para algumas afirmações que versavam sobre as relações humanas e profissionais na escola sob sua responsabilidade. Nas afirmações que tentavam captar como os alunos se relacionam com as aulas, mais da metade dos diretores, 22 e 23 respectivamente, assinalaram frequentemente em "os alunos prestam atenção nas aulas" e "esforçam-se para tirar boas notas". Quando questionados se "os alunos fazem as lições de casa", menos da metade assinalou a mesma alternativa anterior, 15 diretores disseram que frequentemente isso acontece. Ainda 27 diretores afirmaram que frequentemente "os alunos gostam dos seus professores" e 32 disseram o mesmo sobre a afirmação "os alunos sentem-se seguros na escola".

No que diz respeito as relações estabelecidas pelos alunos com as demais pessoas na escola, 24 diretores apontam que os alunos tratam frequentemente os colegas com respeito e 28 afirmam se repetir esse tratamento com professores e funcionários. Os alunos também tratam frequentemente os demais com respeito independentemente da cor da pele (28 respostas), independentemente da religião (29 respostas) e independentemente da opção sexual (27 respostas). 
Os diretores afirmam que os professores frequentemente tratam os alunos com respeito independentemente da cor da pele, religião e opção sexual, respectivamente, para cada opção, 36 diretores assinalaram esta alternativa, 35 e 34 . Para 26 deles, os professores frequentemente escutam os alunos quando eles têm problemas, para 30 diretores os professores frequentemente gostam de seus alunos e 33 afirma que frequentemente os professores esclarecem quais os comportamentos consideram adequados para o relacionamento em sala de aula. Os professores frequentemente ajudam os alunos a resolver os conflitos entre eles para 25 diretores, para 26 frequentemente os professores têm atenção especial com alunos que apresentam dificuldades de aprendizagem e 16 deles afirmam que frequentemente o professor recompensa as turmas por bom comportamento em sala de aula.

Quando perguntados sobre o tratamento dado aos alunos pelos funcionários, todos os diretores entrevistados apontam que estes tratam frequentemente os alunos com respeito independente da cor da pele, religião ou opção sexual. Contudo, com relação a esclarecer aos alunos quais são os comportamentos considerados adequados nos ambientes comuns da escola, 27 apontam que os funcionários o fazem frequentemente e 10 às vezes. Para 25 diretores os funcionários frequentemente ajudam os alunos a resolver os conflitos entre eles e para 12 às vezes os ajudam.

Com relação às regras escolares, todos os diretores afirmam que elas são frequentemente conhecidas pelos alunos e 32 deles afirmam que frequentemente estas são justas. Para 20 diretores as regras frequentemente são elaboradas com a participação dos alunos e para 16 às vezes. Segundo 20 deles, as regras são obedecidas frequentemente. Quando as regras são quebradas, para 27 diretores, frequentemente tem consequências, destes, 25 mandam os alunos para a diretoria. Nos casos de conflito entre os alunos, 33 diretores afirmam que frequentemente os pais são chamados, 25 afirmam que frequentemente há uma conversa coletiva e 33 afirmam que frequentemente os alunos são chamados para conversas individuais. Ainda é indicado por 25 dos entrevistados que, nessas ocasiões, às vezes os alunos são postos para fora da sala e para 8 isso acontece frequentemente.

Com relação às sanções e recompensas aplicadas aos alunos, 27 diretores apontam que os alunos às vezes são muito punidos pela escola e 29 apontam que os alunos são elogiados frequentemente. Para 19 diretores os estudantes são às vezes recompensados por serem bons alunos. Quase a totalidade dos diretores, 35 afirmam que os alunos frequentemente recebem regras claras da escola sobre como devem se 
comportar e 20 asseveram que os alunos frequentemente se comportam de acordo com elas.

Com relação aos três principais lugares onde são registrados os maiores números de ocorrências sobre conflitos na escola, 17 dos diretores apontam a sala de aula como o principal local onde estas ocorrem, seguido pelo momento de saída da escola (15 respondentes), nos corredores entre uma aula e outra (10 respondentes), no momento das refeições (9 respondentes), na recreação (8 respondentes) e no momento de entrada na escola (8 respondentes). Nenhum dos diretores cita a sala dos professores, a sala dos gestores ou a secretaria da escola como espaços conflituosos. Do total de entrevistados, apenas 8 afirmam que situações de violência não acontecem em suas escolas.

\section{Gestão escolar e rede de apoio}

No terceiro bloco de questões, foram descritas algumas situações conflituosas e solicitou-se que os diretores informassem quais órgãos ou quem eles acionariam para solucionar tais problemas. As respostas foram dadas de forma aberta, possibilitando que cada diretor pudesse indicar mais de um órgão, se fosse o caso.

Nos casos de depredação/pichação das dependências externas e/ou internas da escola são acionados, nesta ordem, responsáveis ${ }^{5}$, polícia $^{6}$ e mediação ${ }^{7}$. Em relação aos casos de roubo/furto de equipamentos e/ou a profissionais e alunos, o primeiro órgão a ser acionado é a polícia, seguido de responsáveis. Nas situações de consumo/porte/tráfico de drogas nas dependências e/ou proximidades da escola são acionados polícia, responsáveis e mediação. Casos de consumo de álcool nas dependências e/ou proximidades da escola não ocorrem para 11 diretores e, nas escolas onde ocorrem, a polícia é o órgão mais acionado por 16 diretores e os responsáveis por 11.

Em casos de agressões verbais entre alunos a maioria dos diretores aciona os responsáveis, a mediação e os próprios alunos e/ou a gestão da escola. Já nos casos de agressão física, os dois primeiros órgãos acionados são responsáveis e a mediação e o

\footnotetext{
5 Entende-se como responsáveis pessoas adultas assumem a responsabilidade pelo aluno e que são referência, nesse quesito, para a escola.

${ }^{6}$ Neste trabalho, trata-se genericamente por polícia todo órgão com poder de controle e repressão como polícia militar, polícia civil e/ou ronda escolar.

${ }^{7}$ Acionar a mediação significa, nesse caso, chamar o Professor Mediador Escolar e Comunitário para tentar equacionar o conflito.
} 
terceiro é o Conselho Tutelar. Quando acontece agressão verbal de aluno contra profissionais da escola os diretores afirmam acionar os responsáveis, a mediação e a gestão da escola, no caso de agressão física, em terceiro lugar, a polícia é assinalada como órgão acionado.

Nos casos de agressão verbal contra os alunos por profissionais da escola os órgãos acionados são os mesmos nos casos de agressão verbal cometida por alunos, ou seja, os responsáveis, a mediação e a gestão da escola. Já quando perguntados sobre a ocorrência de agressão física de profissionais da escola contra alunos 12 diretores afirmam que isso não ocorre, 10 diretores acionam os responsáveis e 8 a mediação.

\section{Professores mediadores comunitários: possíveis implicações na dinâmica escolar}

O quarto bloco continha questões específicas sobre as funções do Professor Mediador Escolar e Comunitário (PMEC). De acordo com 20 diretores, a maior mudança observada após a criação da função dos PMECs foi a redução de conflitos. Para 9 diretores há maior contato com os responsáveis pelos alunos e comunidade escolar; 5 afirmam que foi a criação de mais uma função na equipe pedagógica; 5 apontam melhor acompanhamento da frequência dos alunos e redução da evasão escolar; 5 indicam maior disciplina e organização da escola; 3 atribuem ao PMEC o aumento do rendimento acadêmico dos alunos, além de citarem melhor contato com o Conselho Tutelar e redução das depredações patrimoniais. Apenas 1 diretor apontou que não houve mudança significativa com a criação da função.

Quando questionados sobre quais ações o PMEC realiza em cada escola, 15 dos diretores afirmam que sua principal ação é a mediação de conflitos e o atendimento dos alunos; para13 diretores sua principal ação é o desenvolvimento de projetos e organização de palestras para os alunos e comunidade escolar. Para outros 9 diretores, o PMEC é responsável pelo contato com os responsáveis pelos alunos e com a comunidade, além de auxiliar nas ações da equipe gestora, função citada por 6 gestores. O Professor Mediador ainda é responsável por entrar em contato com o Conselho Tutelar para 5 diretores, controlar a frequência e evasão dos alunos para 3 deles, por trabalhar com justiça restaurativa e orientar a equipe de professores para 2 e por atuar como professor substituto em caso de faltas para 1 diretor. 
Em relação às principais dificuldades que o Professor Mediador Escolar e Comunitário enfrenta para realizar o seu trabalho, 11 diretores apontaram o trabalho com os responsáveis pelos alunos, que muitas vezes não comparecem ou não atendem às demais solicitações da escola. Para 9 diretores, a sobrecarga de trabalho e a falta de tempo são o principal desafio do PMEC, seguido pela resistência da equipe escolar às ações que o PMECdesenvolve, conforme 3 respondentes e 2 diretores citam dificuldade no trato com o Conselho Tutelar e falta de formação do PMEC. Do total de diretores entrevistas, 8 deles afirmam que não há dificuldades para o exercício da função em sua escola.

\section{Considerações finais}

Com o objetivo de finalizar este debate, cabe retomar a pergunta instigadora deste estudo: o que pensam os diretores sobre as relações de convivência, as situações de conflitos e o papel do Professor Mediador Escolar e Comunitário (PMEC) na mediação destas situações?

\section{$\mathrm{Na}$ dimensão Relações humanas e profissionais no cotidiano escolar;}

referentes às frequências das afirmações feitas em relação aos alunos, professores, funcionários e às regras estabelecidas, os dados demonstram que, embora a maioria dos diretores afirme que frequentemente os alunos prestam atenção nas aulas, esforçam-se para tirar boas notas, gostam dos seus professores, sentem-se seguros na escola, tratam colegas, professores e funcionários com respeito, independentemente de questões de diversidade; estes são muito punidos pela escola às vezes. O que nos leva a refletir sobre as razões das punições uma vez que, em geral, pelo que afirmam os diretores, os alunos demonstram bom comportamento. Quando perguntados sobre os espaços físicos ou temporais onde as ocorrências de violência mais acontecem na escola, o primeiro lugar é citado é a sala de aula, o que também surpreende, uma vez que em respostas anteriores os diretores afirmaram existir conhecimento e adesão às regras e respeito entre os alunos e profissionais da escola.

No que tange à existência de regras de convivência no espaço escolar, pode-se afirmar que os alunos requerem clareza sobre elas, o que possibilita negociar com a direção, mesmo que suas expectativas não sejam exatamente atendidas, mas pelo menos, ouvidas e levadas em consideração, na medida do possível. Alunos sabem a 
margem de manobra que podem ter em relação ao perfil da gestão da escola, pois "diferentemente de outras atividades de trabalho na indústria ou nos serviços, o grupo de alunos não é uma equipe de colaboradores: ele constitui, para o professor (e para a direção da escola), ao mesmo tempo, o espaço de seu trabalho [...] e seu material" (TARDIF, LESSARD, 2005, p 69).

No tocante à dimensão Gestão escolar e rede de apoio, relativa à quais órgãos ou atores os diretores acionam para solucionar alguns problemas específicos, têm-se como principais atores envolvidos na resolução dos problemas os responsáveis pelos alunos, a polícia e a mediação escolar. Este quadro aponta que, ainda que a mediação tenha papel importante na diminuição dos conflitos, as escolas tendem a envolver ou delegar a atores externos à escola na resolução dos conflitos escolares. Em poucos casos foram registradas resoluções por parte da escola diretamente com os sujeitos envolvidos nos casos.

Já na dimensão PMECs: possíveis implicações na dinâmica escolar, com questões específicas sobre o papel do professor mediador, destaca-se a opinião dos diretores sobre a diminuição dos conflitos gerada pelo trabalho destes professores na escola, bem como a melhora da relação da escola com os responsáveis e comunidade escolar. Contudo, é importante salientar a quantidade de respostas que pontuam o excesso de trabalho e a falta de tempo como os principais entraves ao desenvolvimento da função.

Como se disse no início deste texto, o estudo aqui analisado buscou compreender a opinião de diretores de escolas da rede estadual de São Paulo sobre situações de conflito. Partiu-se do pressuposto que diretores (assim como professores) também são construtores de políticas, pois influenciam fortemente a interpretação que se faz das diretrizes e programas governamentais, envolvendo-se em questões políticas quando decidem aceitá-las, modificá-las, rejeitá-las em seu cotidiano de trabalho, com todas as peculiaridades, possibilidades e limites que configuram as redes de escolas. Em última instância, são os responsáveis pela materialização das diretrizes e programas do governo do qual são parte integrante, (re) interpretando o conjunto legal e normativo.

Identificou-se que a maior parte dos diretores reconhece a importância da função do PMEC na redução e mediação das situações de conflitos na escola. Embora os resultados não possam ser generalizados à rede estadual paulista - que possui 5.500 escolas - os dados indicam tendências apontadas em estudos da área, que merecem atenção, especialmente sobre as formas pelas quais a mediação das situações de conflito 
vem sendo tratadas. É sabido que muitos diretores se vêem frente a situações de conflitos semelhantes e as enfrentam de formas diferentes. Não há receituário ou livro didático orientando sobre o que fazer nesses confrontos, pois as atividades de gestão são impregnadas da experiência individual e social em contextos nos quais interagem aspectos pessoais e profissionais: é a descoberta de si no trabalho; a constituição de processos identitários; a emergência do sentimento de impotência nas situações vicenciadas .

Nessa perspectiva, casos amplamente divulgados pela mídia sobre comportamento de adolescentes e jovens, considerados como casos de indisciplina, por exemplo, poderiam ser melhor equacionados se as políticas públicas de educação investissem em ações de prevenção, que fossem capazes de suscitar nos profissionais da escola mudanças de atitudes e de valores por meio de atividades de formação continuada que incluíssem a discussão, reflexão e análise de situações conflituosas e as medidas adotadas.

AGRADECIMENTOS: CNPq e Fundação Carlos Chagas.

\section{REFERÊNCIAS}

ABRAMOWAY, M.; RUA, M. G. (Coords.). Violência nas escolas. Brasília: Unesco, 2002.

BARROSO, J. (Org.). O estudo da escola. Porto: Porto Editora, 1996.

CARDIA, N. Pesquisa sobre atitudes, normas culturais e valores em relaçãoà violência em 10 capitais brasileiras. Brasília: Ministério da Justiça, Secretaria de Estado dos Direitos Humanos, 1999.

CECCON, C. et al. Conflitos na escola: modos de transformação: dicas para refletir e exemplos de como lidar. São Paulo: CECIP: Imprensa Oficial do Estado de São Paulo, 2009.

CHARLOT, B. A violência na escola: como sociólogos franceses abordamessa questão. Sociologias, Porto Alegre, Ano 4, n. 8, p. 432-443,jul./dez. 2002.

DOURADO, L. F. Políticas e gestão da educação no Brasil: limites e perspectivas. In; Educação \& Sociedade, Campinas, v. 18, n. 100 - Especial, p. 921-946, out. 2007.

HÉBERT-LESSARD, M.; GOYETTE, G.; BOUTIN, G. Investigação qualitativa: fundamentos e práticas. Lisboa: Instituto Piaget, 2008. 
KOETZ, C. M. Atuação da equipe diretiva e avaliações em larga escala: em busca de uma gestão democrática da escola pública. In: WERLE, F. O. C. (org.). Avaliação em larga escala: foco na escola. Brasília: Liber Livro, 2010.

LOPES, R. B. Significações de violências na perspectiva de professores que trabalham em escolas "violentas". Dissertação (Mestrado em Educação).

Universidade Católica de Brasília, Brasília, 2004.

MARTINS, A. M. A gestão de uma escola técnica: desafios pedagógicos. In: Programa de Estudos Pós-Graduados em Educação: psicologia da Educação, PUC/SP. (Org.). Ensino médio e ensino técnico no Brasil e em Portugal. 1 ed. Campinas: Autores Associados, 2005, v. 01, p. 111-136.

MARTUCCELLI, D. Reflexões sobre a violência na condição moderna. Tempo Social. Revista de Sociologia, USP, n. 1, p. 157-175, maio 1999.

SÃO PAULO. Secretaria de Estado da Educação. Resolução SE no 19, de 12/02/2010. Institui o Sistema de Proteção Escolar na rede estadual de ensino de São Paulo e dá providências correlatas. São Paulo: CENP/DRHU, 2010.

SÃO PAULO. Secretaria de Estado da Educação. Seminário de Proteção Escolar: debate temas como bullying e prevenção de conflitos. Disponível em: $<$ http://www.educacao.sp.gov.br/spec/seminario-protecao-escolar-debate-temasbullying-prevencao-conflitos/>. Acesso em: 20 jul. 2015.

TARDIF, M., LESSARD, C. O trabalho docente: elementos para uma teoria da docência como profissão de interações humanas. Petrópolis: Editora Vozes, 2005.

VILlANUEVA, L. F. A. Problemas públicos y agenda de gobierno. México, 1996.

VIANNA, C. P. A feminização do magistério na educação básica e os desafios para a prática e a identidade coletiva docente. In: YANNOULAS, S. C. (org.).

Trabalhadoras: Análise da feminização das profissões e ocupações. Brasília, DF: Abaré, 2013. p. 159-180.

\section{Como referenciar este artigo}

MACHADO, Cristiane.; MARTINS, Angela Maria Martins. Gestão escolar: desafios na mediação das relações de convivência. Revista on line de Política e Gestão Educacional, Araraquara, v.21, n.2, p. 350-362, maio-ago. 2017. Disponível em: <http://dx.doi.org/10.22633/rpge.v21.n.2.2017.9498>. ISSN: 1519-9029.

Submetido em: 05/03/2017

Aprovado em: 15/04/2017 